\title{
POLÍTICA DE INCLUSÃO NA EDUCAÇÃO INFANTIL: AVANÇOS, LIMITES E DESAFIOS
}

\author{
POLÍTICA DE INCLUSIÓN EN LA EDUCACIÓN INFANTIL: AVANCES, \\ LÍMITES Y DESAFÍOS
}

\section{INCLUSION POLICY IN EARLY CHILDHOOD EDUCATION: ADVANCES, LIMITS AND CHALLENGES}

Marilda Moraes Garcia BRUNO ${ }^{1}$

Washington Cesar Shoiti NOZU ${ }^{2}$

RESUMO: Este texto focaliza a política de inclusão de crianças com deficiência na Educação Infantil, a partir da Constituição Federal Brasileira de 1988. Nesse sentido, apresenta a trajetória legislativa desta etapa de ensino, indicadores de matrículas e resultados de pesquisas sobre a temática. Trata-se de um estudo documental e bibliográfico que pretende sinalizar avanços, limites e desafios que se impõem na construção e implementação da proposta de inclusão de crianças com deficiência em creches e pré-escolas. Por fim, conclui que a inclusão na Educação Infantil é um direito social inalienável, enfatizando a necessidade de práticas colaborativas para que o Atendimento Educacional Especializado nessa etapa de ensino não se reduza à instrumentalização da Educação Especial, adstrita somente em termos de acessibilidade e adaptações de recursos e materiais pedagógicos.

PALAVRAS-CHAVE: Política Educacional. Educação Especial. Educação Infantil.

RESUMEN: Este texto se centra en la política de inclusión de niños con discapacidad en la Educación Infantil, a partir de la Constitución Federal Brasileña de 1988. En ese sentido, se busca presentar la trayectoria legislativa en esta etapa de enseñanza, indicadores de matrículas y los resultados de investigaciones sobre la temática. Se trata de un estudio documental y bibliográfico que pretende señalar avances, límites y desafíos que se imponen en la construcción e implementación de la propuesta de inclusión de niños con discapacidad en guarderías y preescolares. Por último, se concluye que la inclusión en la Educación Infantil es un derecho social inalienable y se enfatiza la necesidad de prácticas colaborativas para que el Atendimiento Educativo Especializado en esa etapa de enseñanza no se reduzca a la instrumentalización de la Educación Especial, adscrita sólo en términos de accesibilidad y adaptaciones de recursos y materiales pedagógicos.

\section{PALABRAS CLAVE: Política Educativa. Educación Especial. Educación Infantil.}

\footnotetext{
${ }^{1}$ Universidade Federal da Grande Dourados (UFGD), Dourados - MS - Brasil. Docente do Programa de PósGraduação em Educação. ORCID: <https://orcid.org/0000-0002-1568-2185>. E-mail: mgbruno@uol.com.br ${ }^{2}$ Universidade Federal da Grande Dourados (UFGD), Dourados - MS - Brasil. Docente do Programa de PósGraduação em Fronteiras e Direitos Humanos - UFGD. Doutor em Educação. Bolsista Pesquisador Ingressante da UFGD, na área de Ciências Humanas. ORCID: <https://orcid.org/0000-0003-1942-0390>. E-mail: wcsn1984@yahoo.com.br
} 
ABSTRACT: This text focuses on the inclusion policy of children with disabilities in Early Childhood Education, from the Brazilian Federal Constitution of 1988. In this sense, it presents the legislative trajectory of this education stage, indicators of enrollments and results of researches on the theme. It is a documentary and bibliographical study that intends to indicate advances, limits and challenges that are imposed in the construction and implementation of the inclusion proposal of children with disabilities in daycares and preschools. Finally, it concludes that inclusion in Early Childhood Education is an inalienable social right, emphasizing the need for collaborative practices so that the Specialized Educational Assistance in this stage of education is not limited to the instrumentalization of Special Education, which is only available in terms of accessibility and adaptations of resources and teaching materials.

KEYWORDS: Educational Policy. Special Education. Early Childhood Education.

\section{Introdução}

As políticas de inclusão na Educação Infantil têm ocupado reduzido espaço no debate acadêmico, sobretudo no que tange ao direito social de crianças com deficiência às creches e pré-escolas.

Neste ano, quando comemoramos os trinta anos da Constituição cidadã - que outorga a todas as crianças, desde seu nascimento, o direito à educação, com garantia de Atendimento Educacional Especializado (AEE) àquelas com deficiência - e os dez anos da Política Nacional de Educação Especial na perspectiva da Educação Inclusiva - que enfatiza a inclusão escolar de meninos e meninas com deficiência, transtornos globais do desenvolvimento e altas habilidades/superdotação -, torna-se oportuna uma análise crítica da política de inclusão na primeira etapa da Educação Básica brasileira.

Assim, este artigo tem como propósito tecer análises e reflexões sobre a política de inclusão de crianças com deficiência na Educação Infantil, a partir da Constituição Federal de 1988 e documentação coligida.

Nessa empreitada, partimos do princípio de que as políticas públicas são ações complexas invisíveis, em constante formulação, modificação e transformação. Conforme Palumbo (1989, p. 35), a política é tida como “[...] um processo, ou uma série histórica de intenções, ações e comportamentos de muitos participantes". O autor comenta que uma proposta política não pode ser tocada ou sentida; ela tem de ser inferida a partir de um conjunto de atividades intencionais de muitos agentes e instâncias governamentais responsáveis por sua construção e implementação ao longo do tempo. 
Por esse caminho, teceremos algumas palavras sobre as políticas públicas de inclusão na Educação Infantil a partir de três movimentos: análise de textos político-normativos; apresentação de indicadores de matrículas de alunos com deficiência na Educação Infantil; e revisão de algumas pesquisas científicas sobre a temática.

Nessa direção, pretendemos sinalizar avanços, limites e desafios que se impõem na construção e implementação da proposta de inclusão de bebês e crianças com deficiência em creches e pré-escolas e, dessa maneira, contribuir para a compreensão deste panorama, sobretudo no atual momento histórico de acalorado debate e disputa que permeia a possibilidade de atualização/modificação da política de Educação Especial.

\section{A educação inclusiva para a infância no Brasil: o que mudou?}

A Educação Infantil como direito social é recente no cenário das políticas públicas brasileiras, fruto de lutas dos movimentos sociais, no final da década de 1980, tendo a Constituição Federal de 1998 reconhecido a infância e garantido o acesso de crianças a creches e pré-escolas ${ }^{3}$. Assim, a Educação Infantil foi concebida como dever do Estado e opção da família ${ }^{4}$. Além disso, no tocante à educação de crianças com deficiência, o texto constitucional prevê o AEE a ser ofertado preferencialmente na rede regular de ensino.

Nesse período, a política delineada para a infância tinha cunho assistencialista e não se destinava a todas as crianças; apenas àquelas consideradas sem deficiências. Já as crianças pequenas com deficiência e transtornos globais do desenvolvimento recebiam atendimento educacional em escolas especiais, sobretudo as filantrópicas de caráter terapêutico.

O Estatuto da Criança e Adolescente (ECA), criado pela Lei nº 8.069/1990, oportunizou um avanço para a inclusão de crianças com deficiência no cenário educacional brasileiro, ao apresentar o princípio da proteção integral e assegurar a igualdade de condições para o acesso e permanência em escola pública e gratuita, próxima da residência do educando.

Em 1994, a Política Nacional de Educação Especial, em suas diretrizes gerais, irá apontar a necessidade de estimulação essencial de crianças com necessidades especiais na Educação Infantil e a implementação de “[...] atendimentos especializados às crianças da

\footnotetext{
${ }^{3}$ Até o ano de 2006, a Educação Infantil era responsável pelo atendimento de crianças de 0 a 6 anos de idade. Com a alteração da duração do Ensino Fundamental para 9 anos, com matrícula obrigatória a partir dos 6 anos, a Educação Infantil passou a atender crianças de 0 a 5 anos de idade. A alteração da faixa etária compreendida pela Educação Infantil foi expressa na Emenda Constitucional no ${ }^{\circ}$ 33/2006.

${ }^{4}$ Salienta-se que, somente com a Emenda Constitucional no 59/2009, a Educação Infantil torna-se obrigatória no Brasil. Ainda assim, esta obrigatoriedade adstringe-se à fase pré-escolar, para crianças de 4-5 anos.
} 
primeira infância, de 0 a 3 anos, com base em diagnóstico que envolva procedimentos de avaliação global" (BRASIL, 1994a, p. 59). No mesmo ano, a Política Nacional de Educação Infantil, por sua vez, irá indicar que "[...] as crianças com necessidades especiais devem, sempre que possível, ser atendidas na rede regular de creches e pré-escolas" (BRASIL, 1994b, p. 16).

A Lei de Diretrizes e Bases da Educação (LDB), de 1996, representou um avanço ao posicionar o atendimento à criança para além de um caráter assistencialista, destacando o seu direito a uma educação de qualidade. Nessa direção, assegurou a conquista democrática da igualdade de direitos em relação à Educação Infantil, concebendo-a como a primeira etapa da Educação Básica, com a finalidade do desenvolvimento integral de "todas" as crianças, incluindo as com necessidades educacionais especiais, em seus aspectos físicos, psicológicos, intelectuais e sociais, complementando a ação da família e da comunidade (BRASIL, 1996).

Assim, a LDB trouxe como responsabilidade dos sistemas municipais de educação a estruturação e a organização de creches (0-3 anos) e pré-escolas (4-6 anos, posteriormente, de 4-5 $\operatorname{anos}^{5}$ ) (BRASIL, 1996). Para a implementação dessa proposta, foi elaborado o Referencial Curricular Nacional para a Educação Infantil (BRASIL, 1998), que enfatizava como eixos do projeto pedagógico a diversidade, a interação, a comunicação, o brincar e a socialização das crianças por meio de sua participação nas diversificadas práticas sociais, sem discriminação de espécie alguma. A recomendação para a inclusão é sinalizada no documento, com destaque para uma Educação Infantil que respeite as diferenças e que acolha as crianças com necessidades educacionais especiais e suas famílias (BRASIL, 1998).

As Diretrizes Nacionais para a Educação Especial na Educação Básica, de 2001, colocaram como desafio para os sistemas de ensino e comunidades escolares a construção de uma educação que atendesse à diversidade e às necessidades educacionais especiais de todos os seus alunos. No que concerne à Educação Infantil, esse documento não aprofundou questões de âmbito político, de organização do sistema e da elaboração de projetos pedagógicos inclusivos. Contraditoriamente, enquanto orientava a matrícula de estudantes Público-Alvo da Educação Especial (PAEE) nas escolas comuns da rede regular de ensino, mantinha a possibilidade do AEE substitutivo à escolarização em escolas e classes especiais.

Em meados dos anos 2000, novos contornos políticos passaram a direcionar a educação de crianças com deficiência. Em 2006, o Ministério da Educação publica o documento Política Nacional de Educação Infantil: pelo direito das crianças de zero a seis

${ }^{5}$ Alteração de redação dada pela Lei no 12.796 , de 2013. 
anos, do qual destacamos dois objetivos: a garantia do acesso de crianças com necessidades educacionais às instituições de Educação Infantil e de formação continuada de professores para inclusão de crianças com necessidades educacionais especiais em creches e pré-escolas (BRASIL, 2006). Ainda, as diretrizes do referido documento compreendem que "[...] a educação de crianças com necessidades educacionais especiais deve ser realizada em conjunto com as demais crianças, assegurando-lhes o atendimento educacional especializado mediante avaliação e interação com a família e a comunidade" (BRASIL, 2006, p. 17).

Nesse processo, a publicação, em 2008, da Política Nacional de Educação Especial na Perspectiva da Educação Inclusiva representou um grande avanço conceitual na educação brasileira, definindo a Educação Especial como modalidade não substitutiva à escolarização, que perpassa todos os níveis e modalidades de ensino, trazendo o conceito de AEE complementar ou suplementar à formação dos estudantes e a definição do PAEE - alunos com deficiência, transtornos globais do desenvolvimento e altas habilidades/superdotação (BRASIL, 2008).

A Política Nacional de Educação Especial na Perspectiva da Educação Inclusiva visa orientar os sistemas de ensino a garantir: o acesso, a participação e a aprendizagem do PAEE nas escolas comuns; a transversalidade da Educação Especial (que deve perpassar por todos os níveis, etapas e modalidades de ensino); o AEE; a continuidade nos níveis mais elevados de ensino; formação de professores para o AEE e formação dos demais profissionais da educação para a inclusão; a participação da família e da comunidade; a acessibilidade; a articulação intersetorial das políticas públicas (BRASIL, 2008). Conforme esta Política:

A inclusão escolar tem início na Educação Infantil, onde se desenvolvem as bases necessárias para a construção do conhecimento e seu desenvolvimento global. Nessa etapa, o lúdico, o acesso às formas diferenciadas de comunicação, a riqueza de estímulos nos aspectos físicos, emocionais, cognitivos, psicomotores e sociais e a convivência com as diferenças favorecem as relações interpessoais, o respeito e a valorização da criança. Do nascimento aos três anos, o atendimento educacional especializado se expressa por meio de serviços de intervenção precoce que objetivam otimizar o processo de desenvolvimento e aprendizagem em interface com os serviços de saúde e assistência social (BRASIL, 2008).

Em relação às Diretrizes Curriculares Nacionais para a Educação Infantil, o inciso VII, do $\S 1^{\circ}$, do Art. $8^{\circ}$, da Resolução CNE/CEB $n^{\circ}$ 05/2009, especifica que as propostas pedagógicas das instituições de Educação Infantil devem prever condições para o trabalho coletivo e para a organização de materiais, espaços e tempos que assegurem a acessibilidade de espaços, materiais, objetos, brinquedos e instruções para as crianças com deficiência, 
transtornos globais de desenvolvimento e altas habilidades/superdotação. No entanto, silenciam quanto à operacionalização do AEE nessa etapa de ensino ou por outra forma de atendimento às crianças PAEE.

Para a implementação da política de inclusão na Educação Básica, o governo brasileiro institui as Diretrizes Operacionais para o AEE, por meio da Resolução CNE/CEB, $n^{\circ}$ 4/2009, que preconizam que o AEE deve integrar o Projeto Político-Pedagógico da escola, envolver a participação da família e ser realizado em articulação com as demais políticas públicas. A oferta desse atendimento deve prever em sua organização: sala de recursos multifuncionais para realização do atendimento; matrícula e cronograma de atendimento no AEE; plano de AEE, com identificação das necessidades educacionais específicas dos alunos, definição dos recursos necessários e das atividades a serem desenvolvidas; professores para o exercício da docência no AEE, demais profissionais como tradutor e intérprete da Língua Brasileira de Sinais, guia-intérprete e aqueles que atuam em atividades de apoio. Entretanto, vale observar que, no contexto da prática, essas ações foram implementadas, predominantemente, no âmbito do Ensino Fundamental, sendo que na Educação Infantil ainda imperam inúmeras dúvidas quanto à oferta e a operacionalização do AEE.

A política de financiamento para o AEE adveio por meio do Decreto $n^{\circ}$. 6.571/2008, incorporado pelo Decreto $n^{\circ} .7 .611 / 2011$, dispondo sobre o apoio técnico e financeiro para as seguintes ações: aprimoramento do AEE; implantação de sala de recursos multifuncionais; formação continuada de professores para o AEE; formação de gestores, educadores e demais profissionais da escola para educação inclusiva; adequação arquitetônica de prédios escolares para acessibilidade; elaboração, produção e distribuição de recursos educacionais para acessibilidade; e estruturação de núcleos de acessibilidade nas instituições federais de Educação Superior.

Quanto ao financiamento, a criação do Fundo de Manutenção e Desenvolvimento do Ensino Fundamental (FUNDEF), em 1996, excluiu a Educação Infantil e o Ensino Médio, deixando-os alijados de financiamento para o cumprimento das metas de inclusão e equiparação da igualdade de oportunidades educativas. Em 2007, com o Fundo de Manutenção e Desenvolvimento da Educação Básica e de Valorização dos Profissionais da Educação (FUNDEB), a Educação Infantil passou a receber recursos para o seu desenvolvimento, com previsão, inclusive, a partir de janeiro de 2010, do duplo cômputo de matrículas para os alunos PAEE: uma na sala de aula da escola comum e outra no AEE. 
Em busca pela articulação entre os diferentes sistemas de ensino, o Ministério da Educação lançou o Plano Nacional de Educação (PNE) 2014-2024, tendo em vista a universalização do ensino, com diretrizes, metas e estratégias para eliminação das desigualdades de acesso à educação. Esse documento representa um grande avanço quanto à ampliação da escolarização e das oportunidades educacionais, principalmente quanto à universalização da Educação Infantil na pré-escola para as crianças de 4 a 5 anos de idade e à ampliação da oferta de educação em creches de forma a atender, no mínimo, $50 \%$ das crianças de até 3 anos até o final de vigência do referido PNE.

É louvável a regulamentação de um pacto federativo em torno da elaboração de uma política pública da igualdade de oportunidades à educação desde a mais tenra infância, porém, a meta de ampliação da idade de 4 e 5 anos para cobertura total de oferta para Educação Infantil e a passagem dos 6 anos para o Ensino Fundamental, parece-nos se aproximar de uma estratégias com vistas à minimização de investimentos financeiros e o aproveitamento da estrutura já existente nesta etapa de ensino de forma inadequada para uma proposta de educação para a infância.

Em relação às Diretrizes de Educação Especial para a Educação Infantil, foi publicada a Nota Técnica Conjunta MEC/SECADI/DPEE-SEB/DICEI nº. 02/2015, que dispõe sobre Orientações para a Organização e Oferta do Atendimento Educacional Especializado na Educação Infantil, em creches e pré-escolas, entendidas como estabelecimentos educacionais públicos e privados que educam as crianças de 0-5 anos de idade, por meio da implementação de proposta pedagógica previamente elaborada e desenvolvida por professores habilitados.

Esse documento assegura à criança com deficiência o acesso à Educação Infantil inclusiva, bem como ao AEE, nas redes públicas e privadas de ensino, de forma que, desde os primeiros anos de vida, usufrua da acessibilidade física e pedagógica aos brinquedos, aos mobiliários, às comunicações e informações, utilizando-se da Tecnologia Assistiva como área que agrega os recursos e estratégias de acessibilidade (BRASIL, 2015).

Para tanto, cabe ao professor especializado: elaborar o plano do AEE; identificar e selecionar recursos de Tecnologia Assistiva necessários; produzir e adequar materiais e brinquedos; acompanhar o uso dos recursos verificando sua funcionalidade; analisar o mobiliário e orientar os professores e as famílias quanto aos recursos de acessibilidade a serem utilizados (BRASIL, 2015).

Essas medidas são essenciais para a garantia do direito social à Educação Infantil para todas as crianças com necessidades específicas decorrentes da condição de deficiência que 
vivenciam. No entanto, um grande desafio que se impõe para a implementação dessa política é a formação de professores para o AEE nessa etapa de ensino, considerando que os programas de formação de professores para o AEE pouco contemplam questões teóricopráticas para o atendimento de crianças PAEE na Educação Infantil.

Recentemente, o Ministério da Educação lançou a Nota Técnica nº. 25, em 16 de março de 2016, com orientações para o acolhimento de bebês com microcefalia pela Educação Infantil, indicando que "as creches devem acolher os bebês com microcefalia em ambientes inclusivos, ricos e estimulantes, que ofereçam por meio de ação interdisciplinar, as condições necessárias ao seu desenvolvimento integral” (BRASIL, 2016a). Trata-se de uma orientação pertinente, considerando os elevados índices de bebês com microcefalia decorrentes, em grande parte, dos casos de infecção de gestantes pelo zika vírus.

Tendo em vista a continuidade das ações estratégicas de apoio à inclusão escolar das pessoas com deficiência, o Plano Plurianual (PPA) 2016-2019 prevê ampliar o atendimento escolar de qualidade em todas as etapas e modalidades da Educação Básica e universalizar o atendimento escolar para toda população de 4 a 17 anos com deficiência, transtornos globais do desenvolvimento e altas habilidades/superdotação em classes comuns da rede regular de ensino (BRASIL, 2016b). Assim, problematizando o discurso de universalização, se, por um lado, verifica-se a indução da inclusão dos alunos de 4 a 17 anos considerados PAEE nas escolas comuns, por outro lado, este compromisso, na prática, é silente quanto à população de 0-3 anos da Educação Infantil.

\section{Crianças com deficiência no Brasil: indicadores de inclusão na Educação Infantil}

Durante as discussões para a elaboração da Política Nacional de Educação Especial na Perspectiva da Educação Inclusiva, os dados disponíveis da evolução da Educação Especial no Brasil, levantados pelo Censo Escolar da Educação Básica, apontavam que a inclusão de alunos com deficiência em classes comuns do ensino regular, no período de 1998-2006, teve um crescimento de 640\% (BRASIL, 2008). Entretanto, esse avanço não se observava no âmbito da Educação Infantil, pois cerca de $80 \%$ das matrículas de crianças com deficiência ocorriam em creches e pré-escolas de instituições especializadas.

Em 2006, do total de matrículas de alunos PAEE incluídos na Educação Básica, 16\% alocava-se à Educação Infantil, correspondendo a 112.988 matrículas - 89.083 em escolas/classes especiais e 24.005 em turmas comuns. Estes dados iam de encontro aos "[...] 
estudos nesta área que afirmam os benefícios da convivência e aprendizagem entre crianças com e sem deficiência desde os primeiros anos de vida para o seu desenvolvimento" (BRASIL, 2008). Além disso, revelavam que o vazio deixado pelos diferentes níveis de governo abria a brecha para o fortalecimento das escolas especiais, que se constituem, em particular no interior do país, nas únicas possibilidades de educação e AEE para as crianças com deficiência.

Observávamos, naquele momento, que a ausência de políticas específicas para essa faixa etária, a ausência de transporte, a dependência das famílias e do poder público das instituições filantrópicas e "[...] a exclusão social, em especial dos grupos mais vulneráveis, reforçavam a existência de políticas assistencialistas e privatizantes, limitando de modo significativo as possibilidades das escolas públicas" (FERREIRA, 2006, p. 109).

Entretanto, nos últimos anos, em decorrência das movimentações político-normativas na área educacional brasileira, o cenário das matrículas das crianças PAEE na Educação Infantil passou a ser reconfigurado. Até o ano de 2010, as matrículas desta população eram predominantes em classes/escolas especiais (35.397) em relação às classes/escolas comuns (34.044), porém, a partir de 2011, as matrículas nestes espaços passaram a sobrepor-se, numericamente, em relação àqueles (BRASIL, 2016b).

Nesse percurso, registra-se que, contabilizando as matrículas gerais de crianças PAEE em instituições de Educação Infantil comuns e especializadas, houve um decréscimo de 97.006 matrículas, em 2003, para 64.048 em 2015, representando uma redução de $-34 \%$. Este fenômeno, conforme hipótese do próprio Ministério, “[...] pode ser decorrente do fato de que até 2007 contabilizavam-se matrículas de pessoas com deficiência maior de cinco anos de idade na Educação Infantil, além da queda da taxa de natalidade percebida no país" (BRASIL, 2016b, p. 408).

O Gráfico 1 informa o número de matrículas totais, em classes/escolas comuns e em classes/escolas especiais de alunos PAEE na Educação Infantil, entre os anos de 2007 e 2017. 
Gráfico 1 - Matrículas de Alunos PAEE na Educação Infantil (2007-2017)

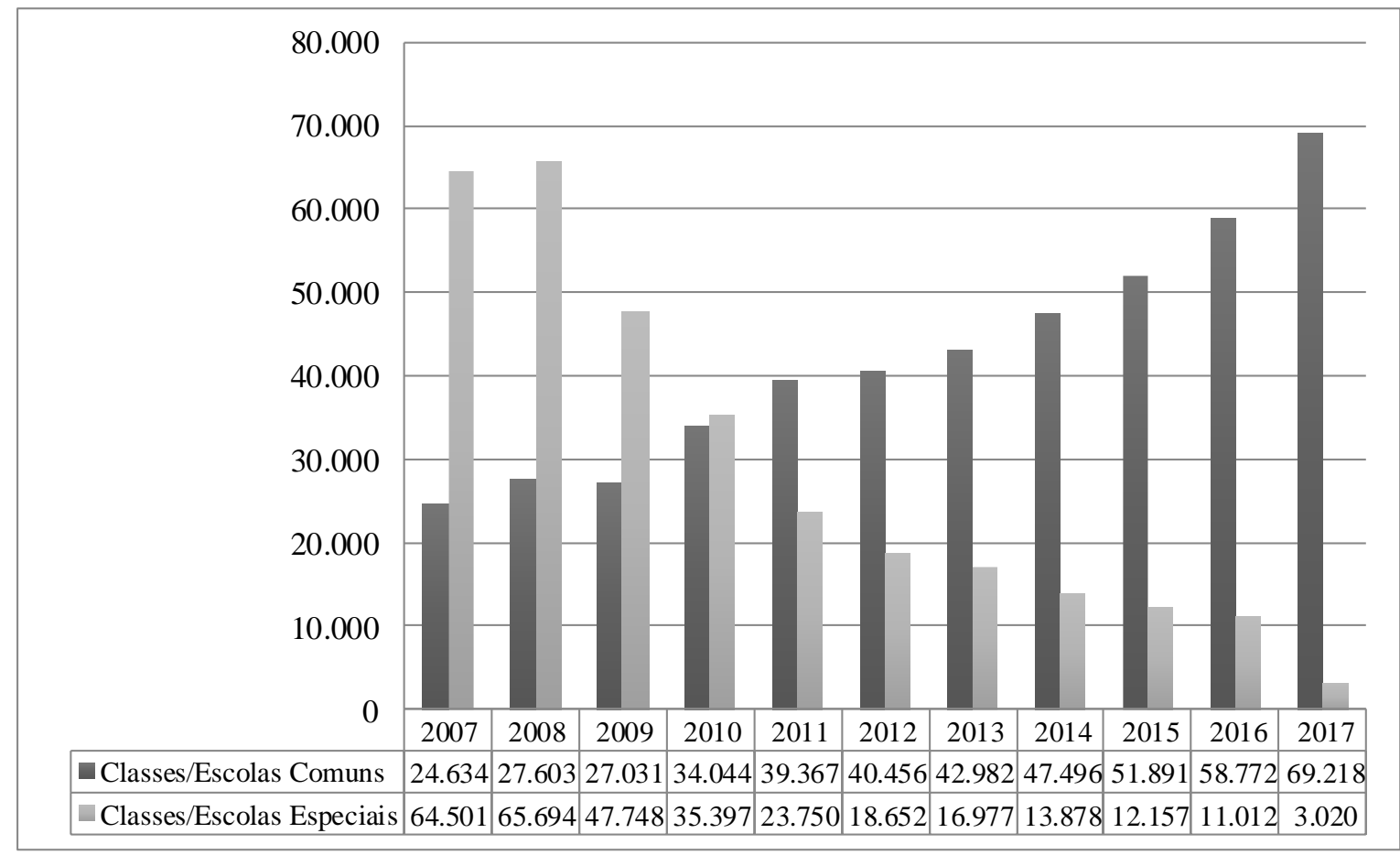

Fonte: INEP (2018)

Como se observa, na última década, em razão da política de inclusão em vigor, acompanhamos significativa evolução de matrículas de crianças PAEE em classes/escolas comuns no âmbito da Educação Infantil.

Ainda, vale destacar que os dados estatísticos do Censo Escolar indicam que, no Brasil, a responsabilidade pela Educação Infantil é de 74,6\% da rede municipal e 24,3\% da rede privada, sendo que $86,1 \%$ das matrículas da pré-escola estão em escolas da zona urbana (BRASIL, 2016b). Quanto aos dados de infraestrutura adequada à pedagogia da infância, apenas 59,3\% dos matriculados têm acesso a parque infantil e 60,5\% dos matriculados na préescola têm acesso a banheiro adequado; somente 43,5\%3 estudam em escolas em que há banheiro adequado a alunos com deficiência ou mobilidade reduzida; a acessibilidade nesse nível de ensino é de 34,2\%: dados que revelam a falta de investimentos e planejamento para a criação de escolas acessíveis e adaptadas às necessidades de qualquer criança (BRASIL, 2016b).

A leitura desses indicadores educacionais constitui-se numa importante ferramenta para a avaliação, o monitoramento e o direcionamento das políticas públicas de inclusão na etapa da Educação Infantil. 


\section{O que revelam as pesquisas?}

Para continuar as reflexões sobre a política de inclusão na Educação Infantil, apresentaremos, na sequência, algumas pesquisas, realizadas em distintas regiões do país, para (re)pensar os (des)caminhos, os contornos, as tensões, as possibilidades e os desafios que se interpõem no processo de implementação desta proposta.

Nesses dez anos, muito se produziu sobre a inclusão no Ensino Fundamental, mas as produções sobre o tema no âmbito da Educação Infantil continuam reduzidas. Bruno (2008) já indicava a importância da inclusão de crianças com deficiência em creches e pré-escolas em salas comuns dos Centros de Educação Infantil. A autora apontava resultados de estudos que sinalizavam a ausência de AEE nessa etapa de ensino, bem como a falta de professores habilitados em Educação Infantil e Educação Especial, as condições precárias das escolas, inadequação do material didático e de recursos pedagógicos, e principalmente o desconhecimento dos professores quanto às necessidades específicas dessas crianças.

Silva (2017) analisou o lugar ocupado por bebês e crianças pequenas com deficiência nas políticas públicas educacionais brasileiras. Para tanto, buscou identificar quem são, quantas são, quais as demandas e os espaços ocupados pelas crianças com deficiência na Educação Infantil. Os dados levantados apontam que o lugar atribuído a estes sujeitos pelo Poder Público e pela sociedade em geral é o "não lugar", espaço de negação de direitos sociais e de cidadania. Assim, o autor indica a urgência de estudos sobre a temática e a efetivação de política públicas que promovam o acesso e a permanência de crianças com deficiência na primeira infância ao direito à educação de qualidade.

Nunes (2015), ao estudar a implementação das políticas de inclusão em instituições de Educação Infantil de municípios goianos, revela o número reduzido de matrículas de alunos PAEE nessa etapa da Educação Básica, sobretudo em creches. Em face das condições oferecidas pelas escolas pesquisadas, que perpassam por uma ideia duplamente assistencialista sobre a criança com deficiência, a autora destaca que a inclusão na Educação Infantil não nasce espontaneamente, mas da intencionalidade dos profissionais da escola por um fazer pedagógico voltado ao atendimento das particularidades das crianças. Nessa direção, sugere a realização de práticas colaborativas entre os professores, com vistas a promover o sucesso e a aprendizagem de todos os alunos.

Freitas (2015) investigou as decorrências das interações entre as crianças com e sem deficiência na constituição destas últimas como sujeitos, em uma instituição de Educação Infantil gaúcha. Os achados sugerem que as crianças apresentam atitudes indicativas de 
inclusão, sendo que aquelas sem deficiência manifestaram crença no potencial de aprendizagem daqueles com deficiência. A autora conclui defendendo o entendimento de que as crianças pequenas devem ser inseridas e interagir em contextos inclusivos, considerando o processo de constituição da personalidade e a internalização de valores e de comportamentos mais voltados à inclusão.

Rondon (2016) pesquisou os indicadores educacionais de matrículas para crianças com deficiência na faixa etária de 0 a 5 anos na Educação Infantil (EI), nos municípios do estado de Mato Grosso do Sul (MS), no período de 2011 e 2013. Os resultados mostram um número muito baixo de crianças com deficiência matriculadas em instituições de Educação Infantil no ensino regular no estado aludido. Ainda, os dados revelam que as matrículas de crianças com deficiência nas pré-escolas são superiores às das creches. Por fim, o autor problematiza o discurso da inclusão, tendo como ponto de análise o encolhimento do direito das crianças de 0 a 3 anos de idade e a universalização às crianças de 4 e 5 anos, na lógica da preparação escolar futura, o que acaba por reforçar a dicotomia entre os dois níveis que compõem a Educação Infantil: a creche e a pré-escola.

Ribeiro (2016) tratou das orientações dos setores de Educação Especial e de Educação Infantil de rede municipal de ensino de São Paulo voltadas ao atendimento educacional de crianças da Educação Infantil PAEE. A legislação do município assegura a prioridade de vagas nas instituições de educação infantil e o AEE, feito por professores especialista, por meio de serviço itinerante de apoio e acompanhamento pedagógico. Contudo, os resultados acenam que a estimulação precoce de crianças de 0 a 3 anos era feita por professores generalistas, com orientações dos professores especialistas itinerantes, cujas visitas ocorriam a partir da solicitação das respectivas instituições. Às crianças de 4 e 5 anos, além desse formato de atendimento, havia a opção de AEE, no contraturno, em salas de recursos multifuncionais. A autora constatou, no lócus pesquisado, que o AEE era predominantemente ofertado no contexto das instituições de Educação Infantil, sobretudo após a ampliação do número de professores especializados para atuar no serviço de itinerância. Diante disso, conclui acerca da necessidade uma atuação conjunta entre os setores de Educação Especial e Educação Infantil para o avanço das políticas e práticas de inclusão.

Lima e Dorziat (2013), ao analisarem os impactos da política de inclusão em creches e pré-escolas da rede municipal de ensino de Campina Grande/PB, sinalizam que vários aspectos precisam ser revistos para a efetivação de práticas pedagógicas mais inclusivas no âmbito da Educação Infantil. Isso porque alguns indícios têm apontado para um cotidiano em 
instituições de Educação Infantil marcado por situações de exclusão, que negam às crianças com deficiência a participação de vivências essenciais para o seu desenvolvimento. Considerando que as fragilidades mais salientes advêm, no cenário estudado, das ações docentes, as autoras defendem a necessidade de formação continuada como uma estratégia fundamental para o avanço do processo educativo inclusivo.

Bridi e Meirelles (2014) examinam a oferta de serviços de Educação Especial na Educação Infantil em uma rede municipal de educação no Rio Grande do Sul. Os dados revelam a oferta de AEE nas instituições de Educação Infantil e predomínio de matrículas de crianças com deficiência em pré-escolas em comparação às creches. Para as autoras, "[...] essa informação poderia estar vinculada ao ingresso mais tardio na escola dos alunos da Educação Especial ou relacionados à própria produção dos processos de identificação e diagnóstico desses alunos" (BRIDI; MEIRELLES, 2014, p. 760). Das crianças identificadas como PAEE, nem todas frequentam o AEE nas escolas infantis ou frequentam esse serviço em instituições especializadas. Ante os resultados, as autoras indicam a necessidade de ampliação das matrículas dos alunos PAEE na Educação Infantil e a oferta dos serviços especializados a essas crianças, com um olhar atento para os processos de identificação e diagnóstico. Ainda, para além dos indicadores numérico-estatísticos, sugerem um movimento que permita a aproximação da comunidade escolar e ação dos professores especialistas para o atendimento às crianças com deficiência na primeira infância.

Carneiro (2012) considera a política de inclusão ainda distante da realidade escolar, uma vez que a sua construção na Educação Infantil implica em pensar em seus espaços, tempos, profissionais, recursos pedagógicos, voltados para a possibilidade de acesso, permanência e desenvolvimento pleno também de crianças com deficiências. Assim, aponta a importância de práticas colaborativas entre o professor especializado e o professor comum que podem transpor barreiras e qualificar o trabalho pedagógico. A prática colaborativa requer alteração na estrutura da escola de forma a modificar uma cultura de trabalho isolado entre os professores e criar uma nova cultura em que os saberes são compartilhados para favorecer a aprendizagem e o desenvolvimento de todos os alunos.

Os resultados das pesquisas elencadas, além de evidenciar um panorama com diversidade de ações, práticas e desdobramentos, podem também trazer alguns indicativos, pistas e (re)direcionamentos para a atual política de inclusão de crianças na primeira infância. 


\section{Algumas considerações finais}

A garantia do direito social à educação e a concepção de que toda creche e pré-escola devam ser inclusivas constituem-se, inegavelmente, em grande avanço conceitual da política educacional brasileira nos últimos anos: o entendimento de que o acesso e a permanência de crianças na Educação Infantil, a partir do nascimento até os 05 anos, são imprescindíveis para o desenvolvimento integral daquelas com deficiências e para a consolidação de um sistema educacional inclusivo, com oportunidades iguais de aprendizagem para todas.

Entretanto, ainda que a produção político-normativa relativa à inclusão educacional de bebês e crianças com deficiência tenha avançado, verificam-se lacunas quanto ao delineamento das formas de operacionalização do AEE na Educação Infantil, o que nos faz questionar: como se efetivará a oferta da Educação Especial para as crianças de 0-3 anos? Constituir-se-á em trabalho colaborativo entre o professor do ensino comum e da Educação Especial? E para as crianças de 4-5 anos, será por meio do serviço itinerante ou no contraturno em sala de recursos? Essas são questões emergenciais, dentre outras, para a gestão da Educação Especial no ensino comum que devem ser pensadas para assegurar a inclusão na primeira etapa da Educação Básica.

Nessa direção, os estudos apontam inúmeros desafios para a efetivação da política de inclusão na Educação Infantil: a materialização do direito de bebês e crianças com deficiência às creches e pré-escolas; o distanciamento de práticas assistencialistas que permeiam a história tanto da Educação Infantil como da Educação Especial; os benefícios das relações interpessoais entre crianças com e sem deficiência em ambientes de respeito às diferenças; a ampliação da oferta de creches para crianças de 0 a 3 anos; a articulação intersetorial entre Educação Especial e Educação Infantil para o fortalecimento das ações inclusivas; a disponibilização de serviços especializados e de apoio à inclusão de crianças na primeira infância; a formação de professores do AEE para atuação na Educação Infantil; o trabalho conjunto entre o professor da Educação Infantil e da Educação Especial.

Diante desse retrato, destacamos a construção de práticas colaborativas para que o AEE na Educação Infantil não se reduza à instrumentalização da Educação Especial, adstrita somente em termos de acessibilidade e adaptações de recursos e materiais pedagógicos, mas tenha como foco o planejamento, a elaboração de estratégias pedagógicas e avaliação conjunta entre professor regente e professor especialista, tendo em vista a promoção do desenvolvimento global $\mathrm{e}$ as oportunidades de aprendizagem que atendam às necessidades 
específicas de todas as crianças, pois, reiteramos, a inclusão na Educação Infantil com qualidade é um direito social inalienável.

\section{REFERÊNCIAS}

BRASIL. Política Nacional de Educação Especial. Brasília, DF: MEC/SEESP, 1994a.

BRASIL. Política Nacional de Educação Infantil. Brasília, DF: MEC/SEF/COEDI, 1994b.

BRASIL. Lei no 9.394/96, de 20 de dezembro de 1996. Estabelece as Diretrizes e Bases da Educação Nacional. Brasília, DF: Senado Federal, 1996.

BRASIL. Referencial Curricular Nacional para a Educação Infantil. Brasília, DF: MEC/SEF/COEDI, 1998.

BRASIL. Política Nacional de Educação Infantil: pelo direito das crianças de zero a seis anos. Brasília, DF: MEC/SEB, 2006.

BRASIL. Política Nacional de Educação Especial na Perspectiva da Educação Inclusiva. Brasília, DF: MEC/SEESP, 2008.

BRASIL. Lei n. 13.005, de 25 de junho de 2014. Aprova o Plano Nacional de Educação PNE e dá outras providências. Brasília, DF: Congresso Nacional, 2014.

BRASIL. Nota Técnica Conjunta n⿳0 02/2015. Orientações para a organização e oferta do Atendimento Educacional Especializado na Educação Infantil. Brasília, DF:

MEC/SECADI/DPEE, 2015.

BRASIL. Nota Técnica no 25/2016. Orientações para o acolhimento dos bebês com microcefalia pela educação infantil. Brasília, DF: MEC/SECADI/DPEE, 2016a.

BRASIL. A consolidação da inclusão escolar no Brasil: 2003 a 2016. Brasília, DF: MEC/SECADI/DPEE, 2016b.

BRIDI, F. R. S.; MEIRELLES, M. C. B. Atos de Ler a Educação Especial na Educação Infantil: reordenações políticas e os serviços educacionais especializados. Educação \& Realidade, Porto Alegre, v. 39, n. 3, p. 745-769, jul./set. 2014.

BRUNO, M. M. G. A construção da escola inclusiva: uma análise das políticas públicas e da prática pedagógica no contexto da Educação Infantil. Revista @ mbienteeducação, São Paulo, v. 1, n. 2, p. 56-67, ago./dez. 2008.

CARNEIRO, R. U. C. Educação inclusiva na educação infantil. Práxis Educacional, Vitória da Conquista, v. 8, n. 12, p. 81-95, jan./jun. 2012. 
FERREIRA, J. R. Educação especial, inclusão e política educacional: notas brasileiras. In: DAVID, R. Inclusão e educação: doze olhares sobre a educação inclusiva. São Paulo: Summus, 2006, p. 85-113.

FREITAS, C. N. Indicadores de inclusão na Educação Infantil e suas implicações na constituição do sujeito. 2015. 142f. Dissertação (Mestrado em Educação) - Universidade Federal de Santa Maria, Santa Maria, 2015.

INEP. Censo Escolar. Disponível em: http://portal.inep.gov.br/censo-escolar. Acesso em: 30 jun. 2018.

LIMA, M. B. B. S.; DORZIAT, A. Cenas do cotidiano nas creches e pré-escolas: um olhar sobre as práticas de inclusão. Trabalhos completos. $36^{\mathrm{a}}$ Reunião Nacional da ANPED, Goiânia/GO, 2013.

NUNES, M. I. C. Crianças público alvo da Educação Especial na Educação Infantil. 2015. 147f. Dissertação (Mestrado em Educação) - Universidade Federal de Goiás, Catalão, 2015.

PALUMBO, D. J. A abordagem de política pública para o desenvolvimento político na América. In: POLÍTICA de capacitação dos profissionais da educação. Belo Horizonte: FAE/IRHJP, 1989, p. 35-61.

RIBEIRO, R. S. Política paulistana de Educação Especial e Infantil para crianças pequenas público-alvo da Educação Especial. 2016. 227f. Dissertação (Mestrado em Educação) - Universidade de São Paulo, São Paulo, 2016.

RONDON, M. M. Educação Infantil e Educação Especial: os indicadores de matrículas nos municípios do Estado de Mato Grosso do Sul (2011-2013). 2016. 125f. Dissertação (Mestrado em Educação) - Universidade Federal de Mato Grosso do Sul, 2016.

SILVA, C. N. O. Primeira infância e situações de deficiências: elementos para uma análise do (não) direito à educação. 2017. 331f. Dissertação (Mestrado em Educação) - Universidade de São Paulo, São Paulo, 2017.

\section{Como referenciar este artigo}

BRUNO, Marilda Moraes Garcia.; NOZU, Washington Cesar Shoiti. Política de inclusão na Educação Infantil: avanços, limites e desafios. Revista Ibero-Americana de Estudos em Educação, Araraquara, v. 14, n. esp. 1, p. 686-701, abr., 2019. E-ISSN: 1982-5587. DOI: 10.21723/riaee.v14iesp.1.12199

Submetido em: 06/08/2018

Aprovado em: 21/09/2018 